\title{
HYPOTHYROIDISM AND ITS RELATIONSHIP WITH LIPID PROFILE IN PATIENTS WITH TYPE II DIABETES MELLITUS.
}

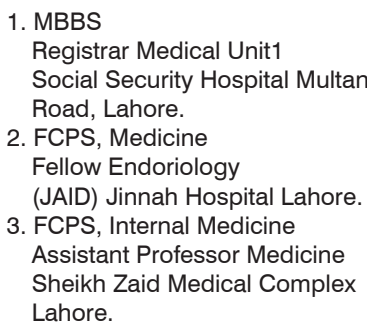

Correspondence Address: Dr. Naseer Nazeer Memon

Registrar Medical Unit1,

Social Security Hospital, Multan Road, Lahore.

dr.naseer84@hotmail.com

Article received on: 03/01/2019

Accepted for publication: 15/07/2019

\begin{abstract}
Naseer Nazeer Memon ${ }^{1}$, Tahir Ullah Khan ${ }^{2}$, Uzma Nasim Siddiqi ${ }^{3}$
ABSTRACT... Objectives: To determine the frequency of hypothyroidism in type II diabetic patients and to compare the lipid profile of diabetic patients with and without hypothyroidism. Study Design: Cross Sectional Study. Setting: Medicine Unit I Shaikh Zayed Hospital Lahore. Period: $5^{\text {th }}$ August 2016 to $5^{\text {th }}$ February 2017. Material \& Methods: A total of 350 patients, aged 35-80 years, of both gender and having type II DM diagnosed at least 1 year ago were enrolled in our study. Fasting (12hr) blood samples were obtained and sent to the laboratory for measurement of serum TSH, total cholesterol, LDL and TGs. Patients with TSH value $>10 \mu \mathrm{g} /$ $\mathrm{ml}$ were labeled as hypothyroid. Two groups (hypothyroid diabetic and euthyroid diabetic) were made and lipid profile was compared in both groups. Results: Frequency of hypothyroidism in type II diabetic patients was recorded as $13.42 \%(n=47)$. When lipid profile of hypothyroid diabetic patients (group I) was compared with euthyroid diabetics (group II), it was noted that patients in group I had mean total cholesterol of $170.32 \pm 12.90 \mathrm{mg} / \mathrm{dl}$ whereas in group II, it was $138.81 \pm 28.89 \mathrm{mg} / \mathrm{dl}$. Mean triglyceride level in group I was $176.21 \pm 15.98 \mathrm{mg} / \mathrm{dl}$, whereas in group II, it was $151.02 \pm 27.78 \mathrm{mg} / \mathrm{dl}$. Mean LDL in group I was $87.17 \pm 15.97 \mathrm{mg} /$ $\mathrm{dl}$, and $71.35 \pm 20.40 \mathrm{mg} / \mathrm{dl}$ in group II. Conclusions: Frequency of hypothyroidism in type II diabetic patients is higher as compared to general population. Moreover, dyslipidemia is significantly higher in hypothyroid diabetics when compared with euthyroid diabetics.
\end{abstract}

Key words: Hypothyroidism, Lipid Profile, Type II Diabetes Mellitus.

Article Citation: Memon NN, Khan TU, Siddiqi UN. Hypothyroidism and its relationship with lipid profile in patients with type II diabetes mellitus. Professional Med $\mathrm{J}$ 2020; $27(3): 472-475$. DOI: 10.29309/TPMJ/2020.27.3.3053

\section{INTRODUCTION}

Thyroid dysfunction in patients with diabetes mellitus (DM) has not gain due attention yet, especially non-insulin dependent type II DM compared to similar etiopathological autoimmune phenomena in type I DM. Hence there is lack of local data emphasizing the relationship between Type II DM and thyroid dysfunction. The prevalence of TD in Type II diabetes is higher compared to normal population. ${ }^{1}$ The prevalence of TD in general population is variable ranging from $6.6 \%$ to $13.4 \% .^{2}$ In the Colorado Thyroid Disease Prevalence study involving 25,862 participants, elevated TSH levels were found in 9.5\% of general population. ${ }^{3}$ In Pakistani diabetic population, $11.66 \%$ patients were found to have sub-clinical hypothyroidism and $35 \%$ patients had overt hypothyroidism. ${ }^{4}$ So there is a wide geographical variability in the prevalence rate observed in different studies. Both disorders independently affect many biochemical processes such as lipid levels that increases cardiovascular risk. Unrecognized and untreated TD may create troubles in management of diabetic complications.

Thyroid hormones affect key enzymatic pathways in lipid metabolism and in turn affect levels of lipoproteins. ${ }^{5}$ Among patients with TSH >12 $\mu \mathrm{g} / \mathrm{mL}$ and normal $\mathrm{T} 4$, a $12 \%$ increase in LDL cholesterol levels were found. This increase did not achieve statistical significance, possibly because of the low number of study subjects and high individual variability. Elevation in serum cholesterol has also been noted in subclinical hypothyroid subjects who have TSH levels between $5.1 \mu \mathrm{g} / \mathrm{mL}$ and $10 \mu \mathrm{g} / \mathrm{mL}^{6}{ }^{6}$

Rationale of this study was to find the prevalence and to evaluate any additive or worsening effect 
of hypothyroidism on lipid profile among Type II diabetics. As there is no local evidence found regarding overall burden in our population, so this study will help us in formulating recommendations regarding screening of thyroid dysfunction among type II diabetics.

\section{MATERIALS \& METHODS}

The present Cross Sectional Study was conducted in Medicine Unit I, Shaikh Zayed Hospital Lahore from $5^{\text {th }}$ August 2016 to $5^{\text {th }}$ February 2017. About 350 cases were enrolled in our study, using $95 \%$ confidence interval with $5 \%$ margin of error. Sampling was done via non probability consecutive sampling method. Patients included in our study were of gender, aged 35 to 80 years and having diagnosed type II diabetes for at least one year. Patients excluded from our study were those with chronic kidney disease and deranged RFTs (creatinine $>1.2 \mathrm{mg} / \mathrm{dl}$ ), chronic liver disease, diabetics on insulin therapy and patients taking statins or lipid lowering drugs. Written informed consent was obtained and demographics of patients (name, age, gender, duration of DM) were noted. Fasting (12hr) blood samples were obtained by using $5 \mathrm{cc}$ BD syringe. All samples were sent to the laboratory for assessment of serum TSH, total cholesterol, LDL and TGs. Patients with TSH level $>10 \mu \mathrm{g} /$ $\mathrm{ml}$ were labeled as hypothyroid. Patients were divided into two groups (hypothyroid diabetic group and euthyroid diabetic group) and their lipid profiles (Total cholesterol, LDL and TGs) were noted. All this information was recorded on Performa. SPSS version 23 was used for data analysis. Quantitative data was expressed as Mean and standard deviation, while Qualitative data was expressed in the form of frequency and percentage. Both the groups were compared for mean total cholesterol, LDL and triglycerides by applying t-test. Data stratification was done for age (35-50, 51-65, 66-80years), gender, smoking, diabetes duration $(1-5,5-10,>10 y e a r s)$ and treatment taken for DM. Post stratification T-test was applied and statistically significant $p$-value was taken as $<0.05$ or less.

\section{RESULTS}

Mean age of our study population was $58.35 \pm 8.13$ years with majority of the patients $(n=240$, $68.64 \%$ ) in age group 51 to 65 years (Table-I). About $57.14 \%(n=200)$ were male and $42.86 \%$ $(n=150)$ were female (Table-II). Frequency of hypothyroidism in type II diabetics was noted as $13.42 \%(n=47)$ (Figur-1). Mean cholesterol in our patients was $138.81 \pm 29.98 \mathrm{mg} / \mathrm{dl}$, Mean triglycerides $154.40 \pm 27.84 \mathrm{mg} / \mathrm{dl}$ and Mean LDL was calculated as $73.4 \pm 20.44 \mathrm{mg} / \mathrm{dl}$. (TableIII). Comparison of lipid profile of both groups showed that Mean cholesterol in hypothyroid diabetics (group I) was $170.32 \pm 12.90 \mathrm{mg} / \mathrm{dl}$ and $138.8 \pm 28.89 \mathrm{mg} / \mathrm{dl}$ in euthyroid diabetics (group II). Mean triglyceride level was $176.21 \pm 15.98 \mathrm{mg} /$ dl in group I and $151.02 \pm 27.78 \mathrm{mg} / \mathrm{dl}$ in group II. Mean LDL was $87.17 \pm 15.97 \mathrm{mg} / \mathrm{dl}$ in group I as compared to $71.35 \pm 20.40 \mathrm{mg} / \mathrm{dl}$ in group || (Table-IV).

\begin{tabular}{|c|c|c|}
\hline Age (in Years) & No. of Patients & $\%$ \\
\hline $35-50$ & 36 & 10.37 \\
\hline $51-65$ & 240 & 68.64 \\
\hline$>65$ & 74 & 21.19 \\
\hline Total & 350 & 100 \\
\hline Mean $\pm S D$ & \multicolumn{2}{|c|}{$58.35+8.13$} \\
\hline \multicolumn{3}{|c|}{ Table-I. Age distribution $(n=350)$. } \\
\hline Gender & No. of Patients & $\%$ \\
\hline Male & 200 & 57.14 \\
\hline Female & 150 & 42.86 \\
\hline Total & 350 & 100 \\
\hline
\end{tabular}

\section{Frequency Of Hypothyroidism}

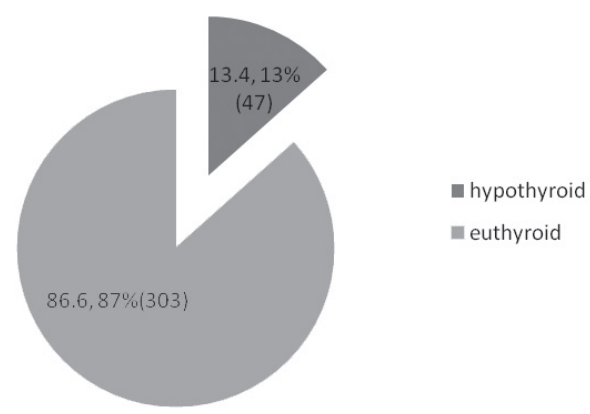

Figure-1. Frequency of Hypothyroidism in Type II DM 


\begin{tabular}{|c|c|c|c|}
\hline \multicolumn{2}{|c|}{ Lipid Profile } & \multicolumn{2}{|c|}{ Mean \pm SD } \\
\hline \multicolumn{2}{|c|}{ Total cholesterol } & \multicolumn{2}{|c|}{$138.81 \pm 28.98$} \\
\hline \multicolumn{2}{|l|}{ Triglyceride } & \multicolumn{2}{|c|}{$154.40 \pm 27.84$} \\
\hline \multicolumn{2}{|l|}{ LDL } & \multicolumn{2}{|c|}{$73.4 \pm 20.44$} \\
\hline \multicolumn{4}{|c|}{ Table-III. Lipid profile of the cases $(n=350)$. } \\
\hline \multirow{2}{*}{$\begin{array}{l}\text { Lipid } \\
\text { Profile }\end{array}$} & Group I & Group II & \\
\hline & Mean & Mean & P-Value \\
\hline $\begin{array}{l}\text { Total } \\
\text { cholesterol }\end{array}$ & $170.32 \pm 12.90$ & $138.8 \pm 28.89$ & 0.0001 \\
\hline Triglyceride & $176.21 \pm 15.98$ & $151.02 \pm 27.78$ & 0.0001 \\
\hline LDL & $87.17 \pm 15.97$ & $71.35 \pm 20.40$ & 0.0001 \\
\hline
\end{tabular}

Table-IV. Comparison of lipid profile of group $\mathbf{i}$ and group ii $(n=350)$.

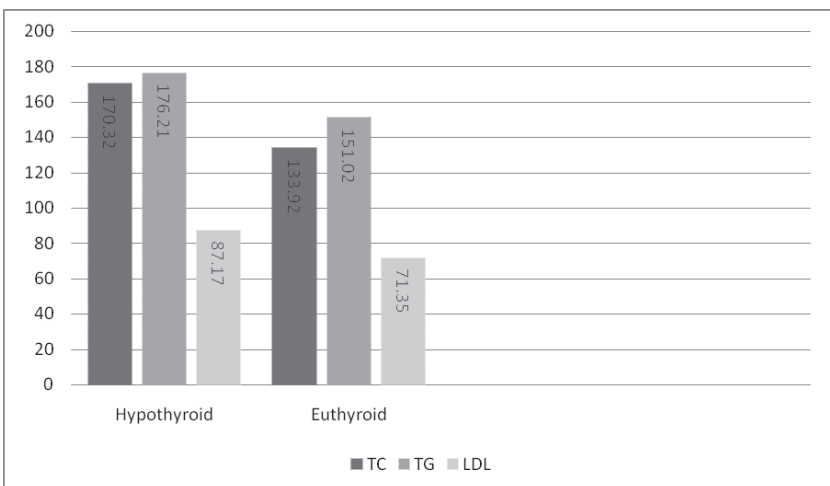

Figure-1. Comparison of lipid profile of Type II dmwith and without Hypothyroidism.

\section{DISCUSSION}

The study was intended to find the prevalence and to evaluate any additive or worsening effect of hypothyroidism on lipid profile among TypeII diabetics considering the fact that there is no local evidence available regarding overall burden of disease in our population and we are unaware of the factual position.

In our study, the frequency of hypothyroidism in type II diabetic patients was recorded as $13.4 \%$ $(n=47)$. Comparison of lipid profile of diabetics patients in both groups (hypothyroid group, euthyroid group) revealed that mean cholesterol in group I was $170.32 \pm 12.90 \mathrm{mg} / \mathrm{dl}$ and 138.81 \pm 28.98 in group II, mean triglyceride level was $176.21 \pm 15.98 \mathrm{mg} / \mathrm{dl}$ in group I and $151.02 \pm$ $27.78 \mathrm{mg} / \mathrm{dl}$ in group II, while mean LDL was $87.17 \pm 15.97 \mathrm{mg} / \mathrm{dl}$ in group I, and $71.35 \pm$ $20.40 \mathrm{mg} / \mathrm{dl}$ in group II. P value was calculated $<0.05$ in all variables. A prospective study done by Ravi Shankar et al found the prevalence of hypothyroidism in type II diabetics to be $16 \%$, predominantly subclinical (15\%), much lower than our study regarding overt hypothyroidism. ${ }^{7}$ Ganong et $\mathrm{al}^{8}$ revealed that cholesterol level is usually elevated in diabetic patients due to an increase in the plasma concentration of VLDL and LDL, but in our study it was significantly higher in patients having dual disorder i.e. hypothyroidism worsening dyslipidemia. A study carried out by Duntas and Leonidas ${ }^{9}$ showed that hyperthyroidism exhibits an enhanced excretion of cholesterol and increased turnover of LDL resulting in a decreased total and LDL-cholesterol, whereas HDL is decreased or not affected. Also, the composition and the transport of lipoproteins are seriously disturbed in thyroid diseases. Again other forms of thyroid dysfunction were not an objective of this study but it is important to note that opposite pathology can exert opposite effects. Rassul, et al. postulated that clinical manifestations of hypothyroidism lead to changes of plasma lipoproteins, which are characterized by elevated LDL cholesterol, and increased ratio of LDL-cholesterol/ HDL-cholesterol. ${ }^{10}$ Hypothyroidism is accompanied by a variety of abnormalities in plasma lipid metabolism, including elevated triglyceride and low-density lipoprotein cholesterol concentrations. Even sub-clinical hypothyroidism can exacerbate the coexisting dyslipidemia commonly found in type II diabetes and further increase the risk of cardiovascular disease. ${ }^{11}$ Duration of DM, treatment duration, gender and smoking were not significantly related to extent of lipid abnormalities in subjects, similarly difference in prevalence of hypothyroidism was also not observed in stratified groups. In a cross sectional study conducted in India, the prevalence of hypothyroidism among type 2 diabetics was about $17.05 \% .{ }^{12}$ Also the prevalence of deranged lipid profile was higher in diabetics than in non-diabetics. In another study ${ }^{13}$, patients having $\mathrm{TSH}>2.5 \mathrm{IU} / \mathrm{ml}$ were having high levels of high density lipoprotein (HDL). In another study from China, there was significant positive association between free T4 and TC (total cholesterol), LDL and HDL $(P<0.05) .{ }^{14}$ Similar observations were recorded in a study conducted on Spanish population. ${ }^{15}$ 
The results of present study along with already existing evidence provide strong basis for formulating screening protocol for thyroid dysfunction among type II diabetics.

\section{CONCLUSIONS}

Frequency of hypothyroidism is higher in type II diabetic patients and is an important contributory factor to disturbed lipid parameters noted in these patients. Further population based studies are needed to be fully aware of thyroid dysfunction and lipid profile abnormalities in type II Diabetic population.

Copyright@ 15 July, 2019.

\section{REFERENCES}

1. Hage M, Zantout MS, Azar ST. Thyroid disorders and diabetes mellitus. Journal of thyroid research. 2011; 2011.

2. Palma CCSSV, Pavesi M, Nogueira VG, Clemente ELS, Pereira Md FBM, Pereira LC. Prevalence of thyroid dysfunction in patients with diabetes mellitus. Diabetology \& metabolic syndrome. 2013; 5(1):58.

3. Canaris GJ, Manowitz NR, Mayor G and Ridgway EC. "The colorado thyroid prevalence study" Archives of Internal Medicine, 2000; 160(4)526-34.

4. Shaikh AW, Memon AS, Sirichand. Frequency of hypothyroidism in Type II diabetic patients. Pak J Med Health Sci. 2009; 2(4):298-301.

5. Jin T, Teng X. Update on lipid metabolism and thyroid disorders. J Endocrinol Diabetes Obes 2014; 2(3):1043.

6. Feld S, Dickey RA. An association between varying degrees of hypothyroidism and hypercholesterolemia in Women: The Thyroid $\square$ Cholesterol Connection. Preventive cardiology. 2001; 4(4):179-82.
7. Ravishankar SN, Champakamalini. A prospective study of thyroid - dysfunction in patients with Type 2 diabetes in general population. I Med Pub Journals 2013; 5:1-9.

8. Ganong WF. Review of Medical physiology. 21ed. Lang MC, Graw Hill, Endocrine Function of the Pancreas. Thyroid Gland 2003; 336-58.

9. Duntas $\mathrm{H}$ and Leonidas $\mathrm{M}$. Thyroid Disease and Lipids. J. Thyroid 2002; 12(4):287-93.

10. Rassul F, Richter V, Kullmann E, Heberling H, Homann M, Zuk U, Rotzsch W, Lahmann D. Lipoprotein Metabolism in patients with disordered thyroid gland functions. Dtsch. Z. verdant. Stoffweshselkr. 1988; 48(2):104-11.

11. Hyden JM and Reaven PS. Cardiovascular disease in diabetes mellitus type (2). J. Lipid Research 2000; 11:519-28.

12. Wolide AD, Zawdie B, Alemayehu T, Tadesse S. Association between thyroid hormone parameters and dyslipidemia among type 2 diabetes mellitus patients: Comparative cross-sectional study. Diabetes \& Metabolic Syndrome: Clinical Research \& Reviews. 2017 Nov 1;11:S257-62. Doi: 10.1016/j. dsx.2016.12.041. Epub 2016 Dec 26.

13. Zhang Y, Lu P, Zhang L, Xiao X. Association between lipids profile and thyroid parameters in euthyroid diabetic subjects: A cross-sectional study. BMC Endocr Disord. 2015 Mar 27; 15:12. doi: 10.1186/ s12902-015-0008-3.

14. Chin KY, Ima-Nirwana S, Mohamed IN, Aminuddin A, Johari MH, Ngah WZ. The relationships between thyroid hormones and thyroid-stimulating hormone with lipid profile in euthyroid men. Int $\mathrm{J}$ Med Sci. 2014 Feb 13; 11(4):349-55. doi: 10.7150/ijms.7104. e Collection 2014.

15. Díez JJ, Iglesias P. Serum cholesterol and triglyceride concentrations in diabetic patients with subclinical hypothyroidism. Endocrinol Nutr. 2014 Oct; 61(8):41925. doi: 10.1016/j.endonu. 2014.01.012. E pub 2014 Mar 26.

\begin{tabular}{|c|c|c|c|}
\hline \multicolumn{4}{|c|}{ AUTHORSHIP AND CONTRIBUTION DECLARATION } \\
\hline Sr. \# & Author(s) Full Name & Contribution to the paper & Author(s) Signature \\
\hline 1 & Naseer Nazeer Memon & $\begin{array}{l}\text { Conceived, designed and did } \\
\text { statistical analysis \& editing of } \\
\text { manuscript. } \\
\text { Data collection and manuscript. }\end{array}$ & 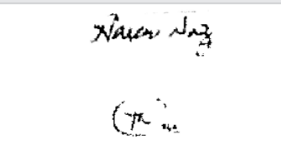 \\
\hline 3 & Uzma Naseem Siddiqi & $\begin{array}{l}\text { Reviewed and final approval } \\
\text { manuscript. }\end{array}$ & $4 \times 2$ \\
\hline
\end{tabular}

